\title{
Fabrication of CNT Dispersion Fluid by Wet-Jet Milling Method for Coating on Bipolar Plate of Fuel Cell
}

\author{
Anas Almowarai, ${ }^{1}$ Yutaro Ueno, ${ }^{2}$ and Yoshiyuki Show ${ }^{2}$ \\ ${ }^{1}$ Department of Science and Technology, School of Science and Technology, Tokai University, \\ 4-1-1 Kitakaname, Hiratsuka, Kanagawa 259-1292, Japan \\ ${ }^{2}$ Department of Electrical and Electronic Engineering, School of Engineering, Tokai University, \\ 4-1-1 Kitakaname, Hiratsuka, Kanagawa 259-1292, Japan \\ Correspondence should be addressed to Anas Almowarai; 5btad001@mail.u-tokai.ac.jp
}

Received 31 August 2015; Revised 28 October 2015; Accepted 2 November 2015

Academic Editor: Yoke K. Yap

Copyright (C) 2015 Anas Almowarai et al. This is an open access article distributed under the Creative Commons Attribution License, which permits unrestricted use, distribution, and reproduction in any medium, provided the original work is properly cited.

\begin{abstract}
Water based carbon nanotube (CNT) dispersion was produced by wet-jet milling method. Commercial CNT was originally agglomerated at the particle size of less than $1 \mathrm{~mm}$. The wet-jet milling process exfoliated CNTs from the agglomerates and dispersed them into water. Sedimentation of the CNTs in the dispersion fluid was not observed for more than a month. The produced CNT dispersion was characterized by the SEM and the viscometer. CNT/PTFE composite film was formed with the CNT dispersion in this study. The electrical conductivity of the composite film increased to 10 times when the CNT dispersion, which was produced by the wet-jet milling method, was used as a constituent of the film. Moreover, the composite film was applied to bipolar plate of fuel cell and increased the output power of the fuel cell to 1.3 times.
\end{abstract}

\section{Introduction}

Carbon nanotubes (CNTs) have attracted considerable attention due to their exceptional electronic, mechanical, optical, and chemical properties $[1,2]$. Because of these superior properties, CNTs have been widely studied as candidate materials for use in cold cathodes for field emission display (FED) technology [3,4], electrochemical sensors [5], and hydrogen storage materials [6]. Moreover, CNTs are ideal filler materials for polymers due to their exceptional strong mechanical property and high electrical conductivity [7, 8]. It has been reported that addition of $1 \mathrm{wt} . \%$ multiwall CNTs into polystyrene resulted in $36-42 \%$ and $25 \%$ increase in elastic modules and break stress [8]. Improvements of mechanical properties by addition of CNTs into polymers have been reported by various studies [9-13]. On the other hand, high electrical conductivity of CNT modifies various polymer to be electrically conductive, because CNTs form continuous conducting networks in the polymer $[9,11,14]$. These composite polymers are widely fabricated by mixture of CNT and polymer in a suitable solvent $[8,15,16]$. Therefore, fabrication of a well-dispersed and long-term stable CNT dispersion in various liquid medium is critical to improve the characteristics of the CNT composite polymer, such as the mechanical properties and the electrical conductivity. Moreover, the CNT dispersion is also required to be low viscosity, because the CNTs in the low viscosity dispersion are able to uniformly disperse in polymer by mixing process.

CNT dispersion is fabricated by various methods such as sonication [17, 18], centrifugal mixing [19], high speed stirring [20], and ball milling [21]. These fabrication methods successfully disperse single wall or multiwall CNTs in various liquid medium such as water, organic solvent, and ionic liquid. Moreover, this fabricated CNT dispersion was applied to the formation of the CNT composite polymers.

Wet-jet milling method is recently employed to disperse CNTs in various liquid medium [22-26]. The electrical and mechanical properties of the CNT composite polymer, which was formed from this CNT dispersion, have been reported. Sekitani et al. reported that single-walled carbon nanotube (SWNT) was dispersed in ionic liquid by the wet-jet milling method [22]. The produced CNT dispersion 
achieved forming the electrically conductive rubber with the conductivity of more than $100 \mathrm{Scm}^{-1}$. Moreover, the rubber-like stretchable active-matrix display was constructed by using the conductive rubber dispersing the CNTs. These reports show that the wet-jet milling method exfoliates aggregated CNTs and disperses the exfoliated CNTs into the liquid medium without shortening CNT length.

In this study, CNTs were dispersed in water by wetjet milling method. The produced CNT dispersion was investigated by the SEM and the viscometer. Moreover, the CNT/PTFE composite film was formed with the CNT dispersion fluid. The electrical conductivity of the composite film was evaluated. From these evaluations, the dispersion process of the CNTs by the wet-jet milling method and the correlation between the viscosity of CNT dispersion and the electrical conductivity of the CNT/PTFE composite film are discussed. Moreover, the CNT/PTFE composite film was coated on bipolar plates of fuel cell. Influence of the film coating on the output power and the inner impedance of the fuel cell is discussed.

\section{Experiments}

2.1. Preparation and Characterization of Aqueous MWCNT Dispersion. Multiwall carbon nanotube (MWCNT), Nanocyl NC7000 (Nanocyl S.A., Sambreville, Belgium), was used as a constituent of the dispersion fluid. The CNT and a dispersant were added into water and mixed by planetary centrifugal mixer (Thinky Co.) for $30 \mathrm{~min}$. Polyoxyethylene (100) stearyl ether (Brij S100, Sigma-Aldrich) was used as the dispersant. The concentrations of both the CNT and the dispersant were $1 \mathrm{wt} . \%$. The CNT was dispersed into water using highpressure wet-jet milling equipment (Nano-Jet Pal, JN 5, Jokoh Co., Japan).

Figure 1 shows schematic diagram of a dispersion unit of the wet-jet milling equipment. The dispersion unit is composed of two inlets and one outlet. There is a small nozzle with the diameter of $0.1 \mathrm{~mm}$ at the connection point. The CNT suspension was flowed into both inlets at high pressure of $50 \mathrm{MPa}$ and was passed through the nozzle at high speed. The streams of the CNT suspension from two inlets collided with each other at the nozzle. By this process, the CNTs, which had been originally agglomerated in the suspension, were exfoliated to individual CNTs and were dispersed into the water. The CNT dispersion, which was drained from the outlet by this process, was flowed into the inlets as 2 nd time. The wet-jet milling process was performed up to 70 times.

The rheological characteristics of the CNT dispersion fluids were measured using a Sine-wave Vibro Viscometer (SV-10, A\&D, Japan) at $24^{\circ} \mathrm{C}$. Moreover, the size of CNT particles in the dispersion fluid was observed by scanning electron microscopy (SEM) (FE-SEM S-4800, Hitachi HighTechnologies Co.). For the SEM observation, the CNT dispersion fluid was dropped on silicon substrate and was dried as sample preparation.

2.2. Preparation and Characterization of CNT/PTFE Composite Film. CNT/PTFE composite film was formed from CNT and polytetrafluoroethylene (PTFE) dispersion fluids.

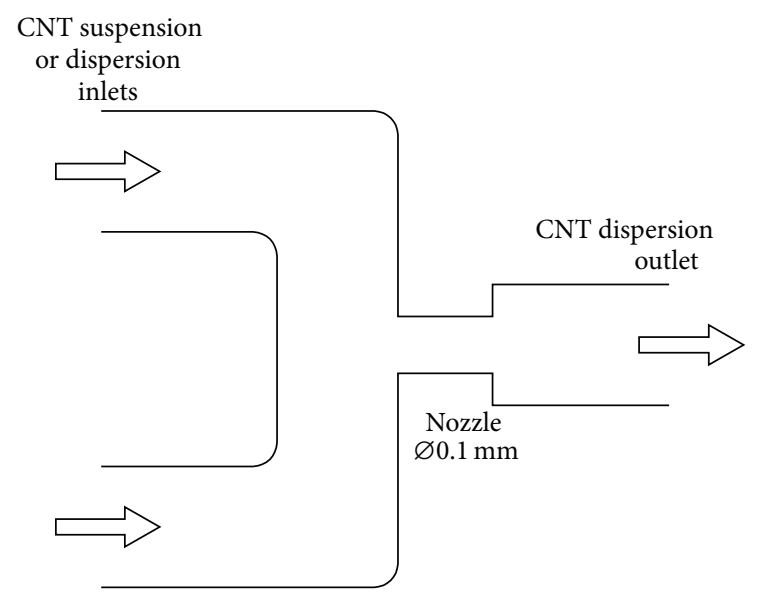

FIGURE 1: Schematic diagram of a dispersion unit of the wet-jet milling equipment.

The CNT dispersion was produced by the wet-jet milling method. The separate CNT and PTFE dispersions were mixed and stirred by ultrasonic agitation for $20 \mathrm{~min}$. This mixed fluid was applied to glass substrate by doctor blade method. The sample was dried in the atmosphere for $30 \mathrm{~min}$ then heated at $350^{\circ} \mathrm{C}$ for $5 \mathrm{~min}$. The CNT/PTFE composite film with the thickness of $10-20 \mu \mathrm{m}$ and the CNT concentration of $25 \mathrm{wt} . \%$ was formed by this process. The electrical conductivity of the CNT/PTFE composite film was measured using four-point probe method (R6243 voltage current source monitor, Advantest, Japan).

2.3. Fabrication of Fuel Cell Using Bipolar Plates Coated with CNT/PTFE Composite Film. The CNT/PTFE composite film with the CNT concentration of $25 \mathrm{wt} . \%$ was applied to stainless steel (316SS) bipolar plates of fuel cell. The polymer electrolyte fuel cell (PEMFC) was assembled with the bipolar plates, which were coated with the CNT/PTFE composite film. Nafion 117 was used as the polymer electrolyte of the PEMFC. The anode and the cathode electrodes contained platinum catalyst, which was supported on acetylene black powder at the loading of $0.25 \mathrm{mg} / \mathrm{cm}^{2}$. Carbon paper was used as gas diffusion layer. The membrane electrode assembly (MEA) was $4 \times 4 \mathrm{~cm}^{2}$ in the size. Humidified hydrogen and oxygen gases were flowed into the anode and the cathode electrodes, respectively, both at $1000 \mathrm{~mL} / \mathrm{min}$. Characterization of the output power and the inner impedance was performed to the fuel cell.

\section{Results and Discussions}

3.1. Production of CNT Dispersion Using Wet-Jet Milling Method. Figure 2 shows photographs of (a) CNT suspension without applying wet-jet milling process and (b) CNT dispersion produced by using wet-jet milling method. The suspension of CNT without applying the wet-jet milling process showed sedimentation of CNT at the bottom of the bottle. Dispersed CNTs in the supernatant seem to be few in number, because it was transparent. On the other hand, the 


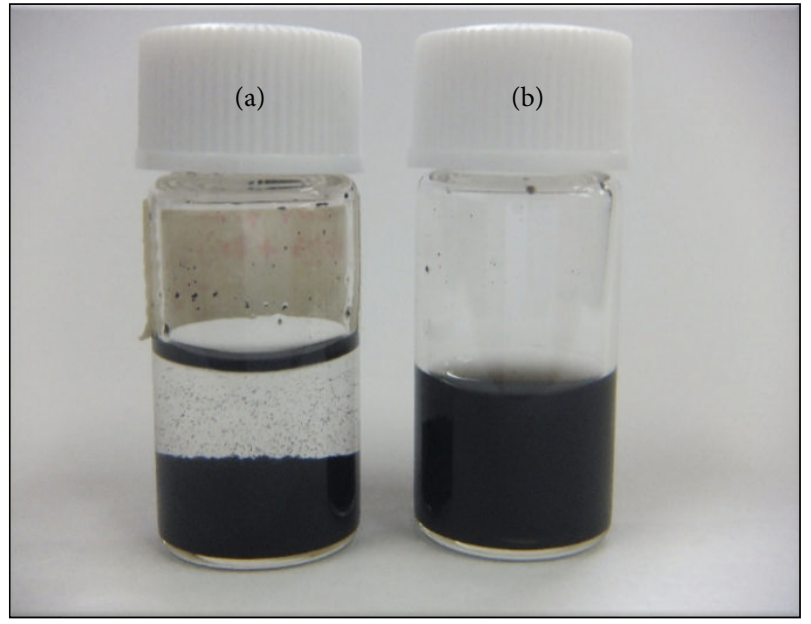

Figure 2: Photograph for (a) the CNT suspension without using wet-jet milling process and (b) the CNT dispersion with using wetjet milling process.

sample, which applied the wet-jet milling process, did not show sedimentation of CNT for more than a month, even if the processing times number was 1 . This result indicates that the wet-jet milling process allows dispersing the CNT into water. Moreover, the produced CNT dispersion is stable although the CNT concentration has high value of $1 \mathrm{wt} . \%$.

Figure 3 shows SEM images of CNT suspension (a) before and (b) after mixing using planetary centrifugal mixer. The CNT suspension before the mixing showed large agglomerates of CNT with the size of up to $1 \mathrm{~mm}$. The size of the agglomerates was decreased to $300 \mu \mathrm{m}$ by applying the planetary centrifugal mixing. However, the individual CNT, which was exfoliated from the agglomeration of CNT and was dispersed in water, was not observed for both samples.

Figures 3(c)-3(f) show SEM images of the CNT dispersion after wet-jet milling at various processing numbers. The CNT dispersion, which was produced by 1 time of the wet-jet milling process, contained the CNT particles with the size of $200 \mu \mathrm{m}$, as shown in Figure 3(c). This particle size was smaller than that of the sample after the planetary centrifugal mixing. The region besides the CNT particles showed a rough surface, which is different from the surface of silicon substrate. High magnification SEM observation showed that the individual CNTs existed on the silicon substrate. Therefore, the wet-jet milling process is considered to exfoliate the CNTs from the agglomerated CNT.

The size and the number of CNT particles decreased with an increase in the number of the jet-milling processes. CNT particles were not observed for the samples above the processing times number of 30 . The roughness of the region existing in the individual CNTs also decreased with an increase in the processing number. Above the processing times number of 30 , the surface was smooth enough not to be observed by the low magnification SEM investigation, although the exfoliated single CNTs existed on the substrate. The smooth surface indicates that the exfoliated single CNTs were uniformly dispersed in water by using the wet-jet milling method.
Figure 4 shows high magnification SEM images of CNT dispersion (a) before and (b) after applying 70 times of wet-jet milling processing. The CNTs in both samples were approximately $25 \mathrm{~nm}$ in the diameter and $1.5 \mu \mathrm{m}$ in the length. From both SEM images, drastic changes of the diameter and the length were not observed. This investigation indicates that the wet-jet milling process has no effect on degrading, defecting, or the size of CNT.

Figure 5(a) shows the dependence of the wet-jet milling processing times number on the viscosity of CNT dispersion. This figure also shows the viscosity of the CNT suspension without applying the wet-jet milling process. The CNT suspension without the wet-jet milling process showed low viscosity of $1.9 \mathrm{mPa} \cdot \mathrm{s}$. The viscosity of CNT dispersion increased to $48 \mathrm{mPa} \cdot \mathrm{s}$ by applying wet-jet milling process once. However, the viscosity decreased to $2 \mathrm{mPa} \cdot \mathrm{s}$ with an increase in the wet-jet milling processing times number up to 70 .

The CNT/PTFE composite film was formed with the CNT dispersion. Figure 5(b) shows the dependence of the wet-jet milling processing times number, which was carried out to produce the CNT dispersion, on the electrical conductivity of the CNT/PTFE composite film. No electrical conduction was observed for the composite film, which was formed using the CNT suspension without applying the wet-jet milling process, although the CNT was contained in the film. On the other hand, the electrical conduction was observed for the CNT/PTFE composite film formed with the CNT dispersion, which was produced by the wet-jet milling method. At 1 time of the wet-jet milling process, the composite film showed the electrical conductivity of $2.7 \mathrm{~S} / \mathrm{cm}$. The electrical conductivity of the CNT/PTFE composite film was within the range of $2-3 \mathrm{~S} / \mathrm{cm}$ up to 6 times of the wet-jet milling process. The electrical conductivity increased to $14 \mathrm{~S} / \mathrm{cm}$ by applying the process at 8 times. With increasing the processing number from 8 to 70 times, the electrical conductivity gradually increased up to $22 \mathrm{~S} / \mathrm{cm}$.

The suspension without the wet-jet milling process contains the large agglomerates of CNTs. Few individual CNTs are contained in the suspension, although the planetary centrifugal mixing is carried out. This CNT suspension shows the low viscosity similar to pure water, because the CNT agglomerates with the size of $300 \mu \mathrm{m}$ contribute low external specific surface and cause the low viscosity of the CNT suspension [27]. The agglomerated CNTs do not form an electrical network in the CNT/PTFE composite film, because high percolation threshold, at which electrical conduction in composite film was formed [28], is required. Therefore, the composite film containing them has no electrical conduction.

The wet-jet milling process exfoliates individual CNTs from the agglomerates, in addition to a decrease in the number and the size of agglomerates. The dispersion containing the individual CNTs, which is formed by the jet-milling process of 1 time, shows high viscosity of $48 \mathrm{mPa} \cdot \mathrm{s}$. The increase of the viscosity results from an increase in external specific surface of CNT [27], which is due to the decrease of agglomerate size and the exfoliation of individual CNTs by the jet-milling process. On the other hand, the viscosity of the CNT dispersion was decreased by applying the jet-milling 


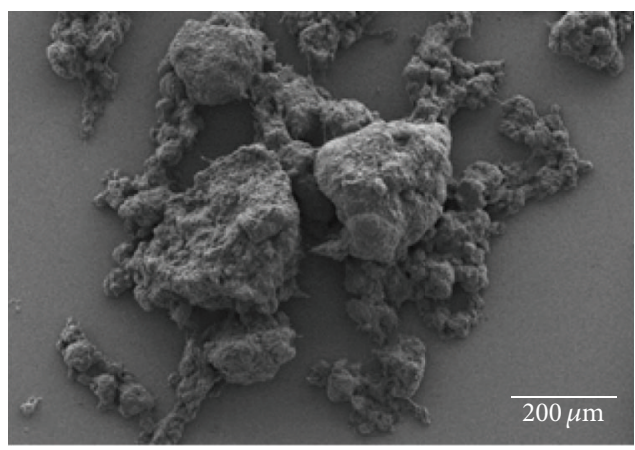

(a) Before mixing

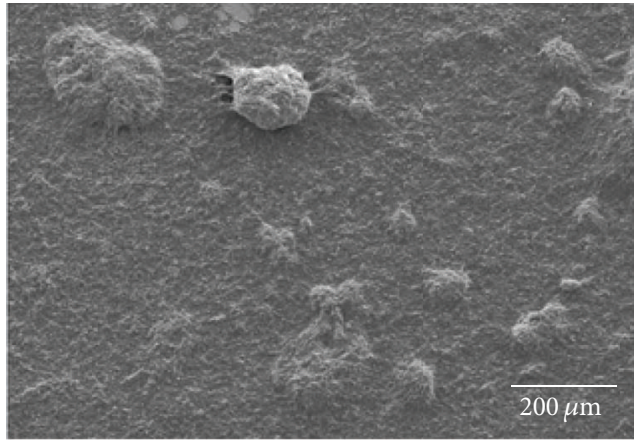

(c) 1 time

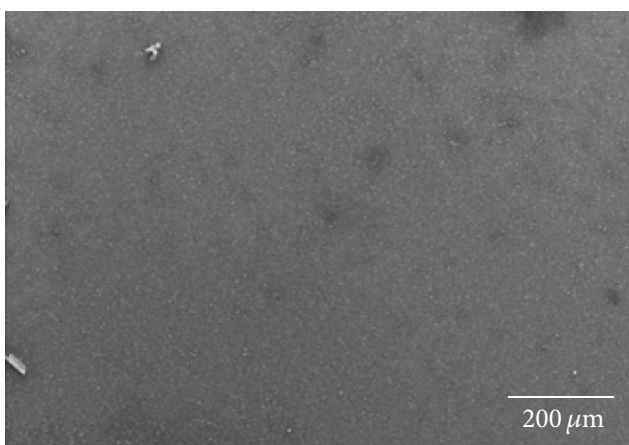

(e) 30 times

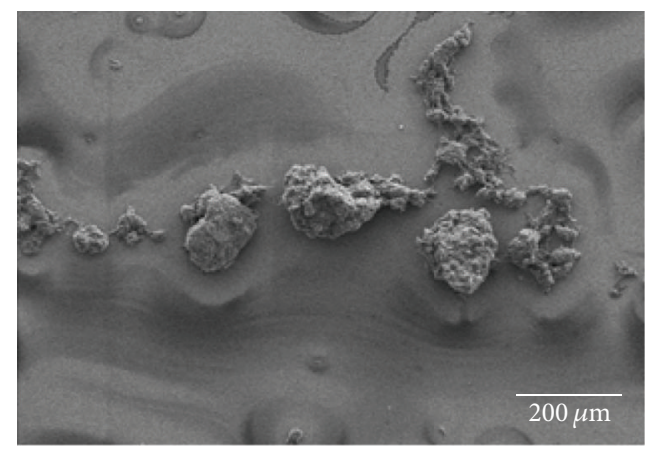

(b) After mixing

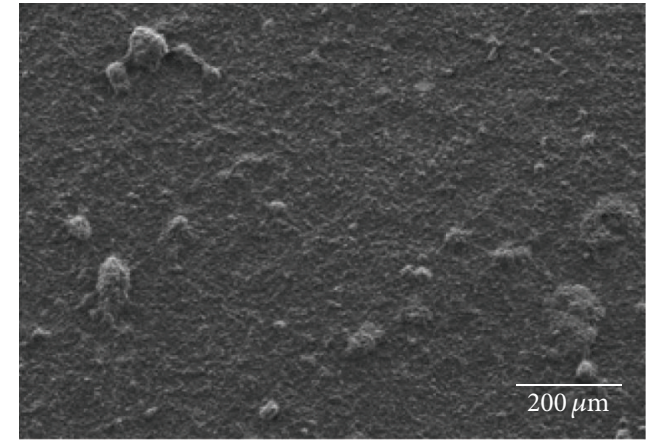

(d) 4 times

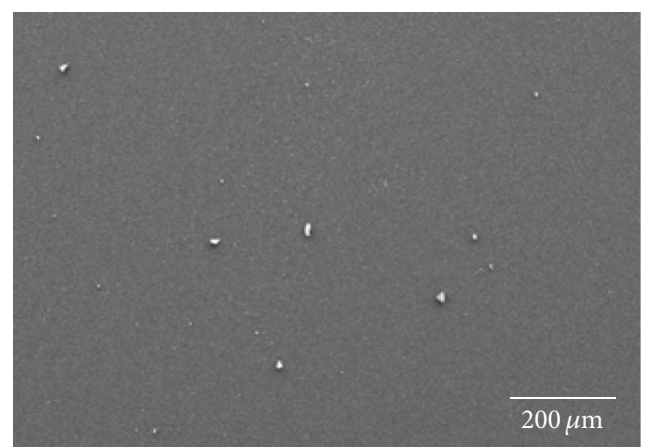

(f) 70 times

FIGURE 3: Low magnification SEM images of CNT in the suspension (a) before mixing and (b) after mixing using planetary centrifugal mixer. SEM images of CNT in the dispersion after wet-jet milling process at various processing numbers, (c) 1 time, (d) 4 times, (e) 30 times, and (f) 70 times.

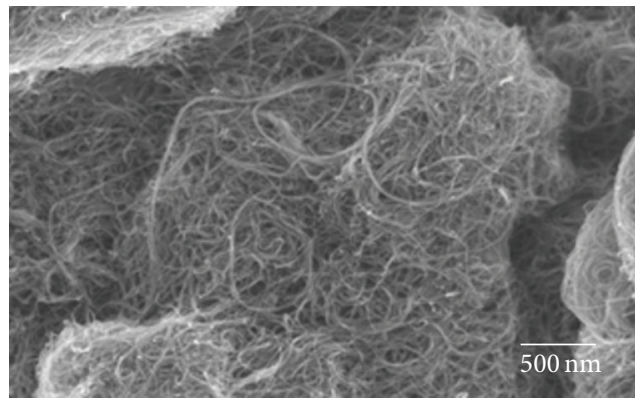

(a) Before wet-jet milling

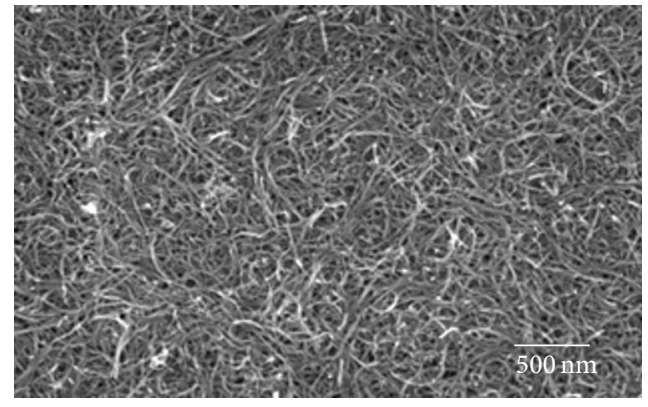

(b) After wet-jet milling

FIGURE 4: High magnification SEM images of CNT in the dispersion (a) before and (b) after the wet-jet milling process of 70 times. 


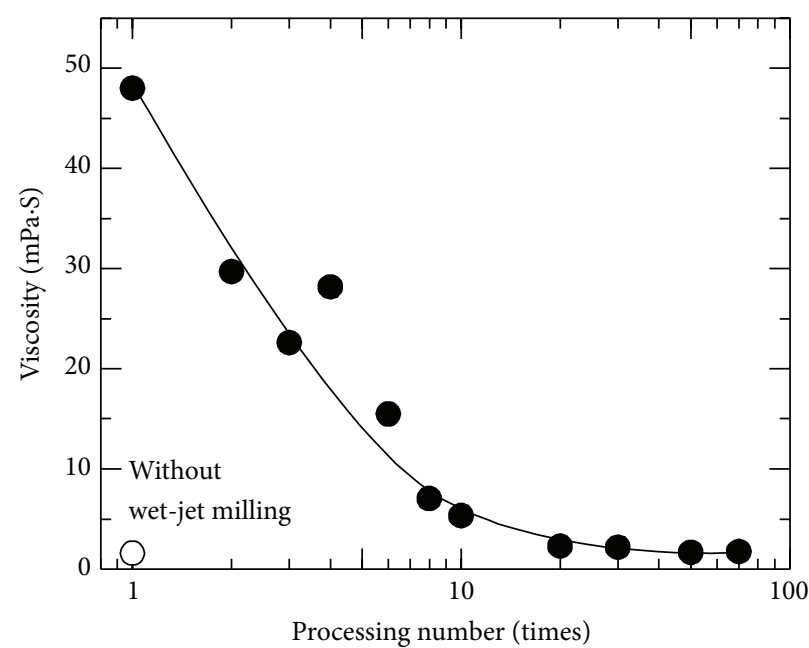

(a)

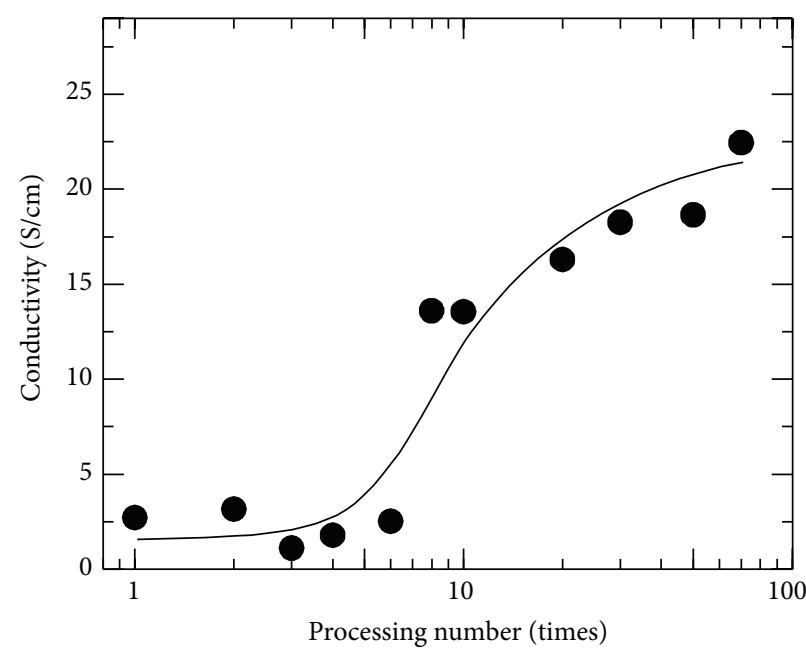

(b)

FIGURE 5: (a) Viscosity of CNT dispersion formed by the wet-jet milling process at various processing numbers and (b) electrical conductivity of the CNT/PTFE composite film. The CNT/PTFE composite film was formed from the CNT dispersion, produced by the wet-jet milling at various processing numbers.

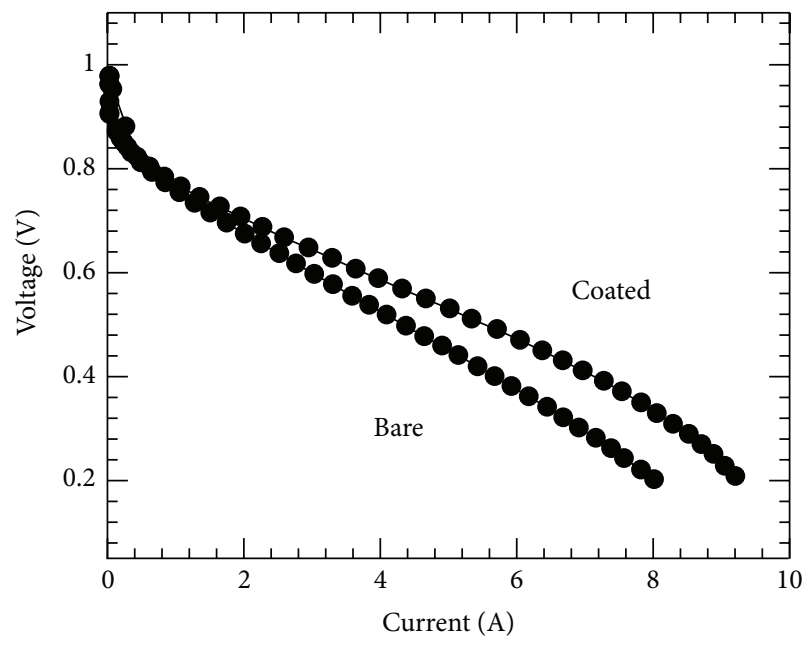

(a)

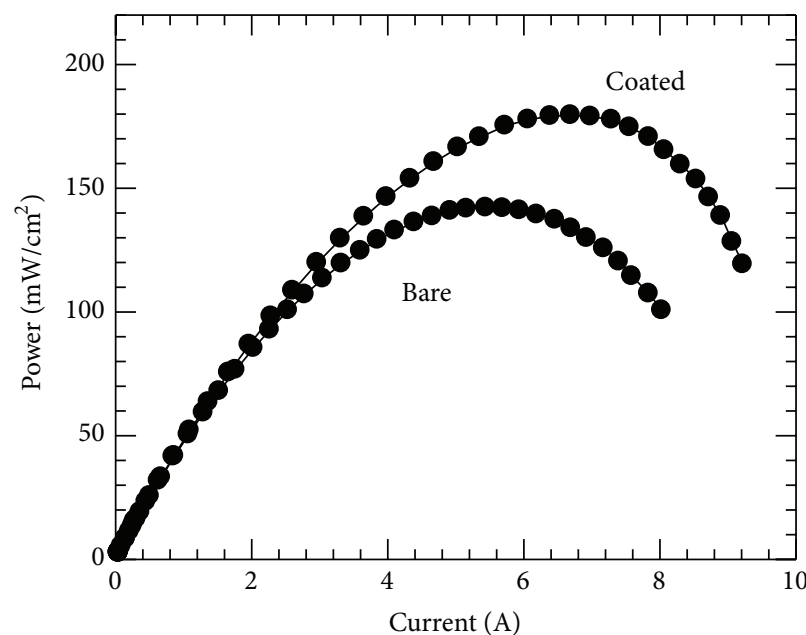

(b)

FIGURE 6: Dependence of the current on (a) the output voltage and (b) the output power for the fuel cells assembled with the bare stainless steel bipolar plate (without coating) or the stainless steel bipolar plate coated with the CNT/PTFE composite film.

above 2 times. The decrease in the viscosity indicates that the CNTs are uniformly dispersed in the water by applying the wet-jet milling process, because high shearing makes the nanotubes align with the flow direction, thus making the viscosity decrease [29].

The electrical conductivity of the CNT/PTFE composite film increases to $22 \mathrm{~S} / \mathrm{cm}$ with an increase in the process time of the wet-jet milling, which is used for producing the CNT dispersion. The wet-jet milling process uniformly disperses CNTs in the water. Therefore, it is possible to distribute the CNTs in the CNT/PTFE composite film uniformly, when the CNT dispersion, which applied the jet-milling at higher process time, is used as a constituent of the composite film.
The uniform distribution of the CNTs in the composite film increases the electrical conductivity of the film, even if the CNT in the film has the same concentration.

\subsection{Coating of CNT/PTFE Composite Film on Bipolar Plates} of Fuel Cell. The CNT/PTFE composite film was formed with the CNT dispersion, which was produced by the jet-milling process, and was applied to the stainless steel (SS) bipolar plate of fuel cell. Figure 6(a) shows the dependence of the current on the output voltage for the fuel cells assembled with the bare SS bipolar plate (without coating) or the SS bipolar plate coated with the CNT/PTFE composite film. Both fuel cells showed the same open voltage of $1 \mathrm{~V}$. The output voltage 


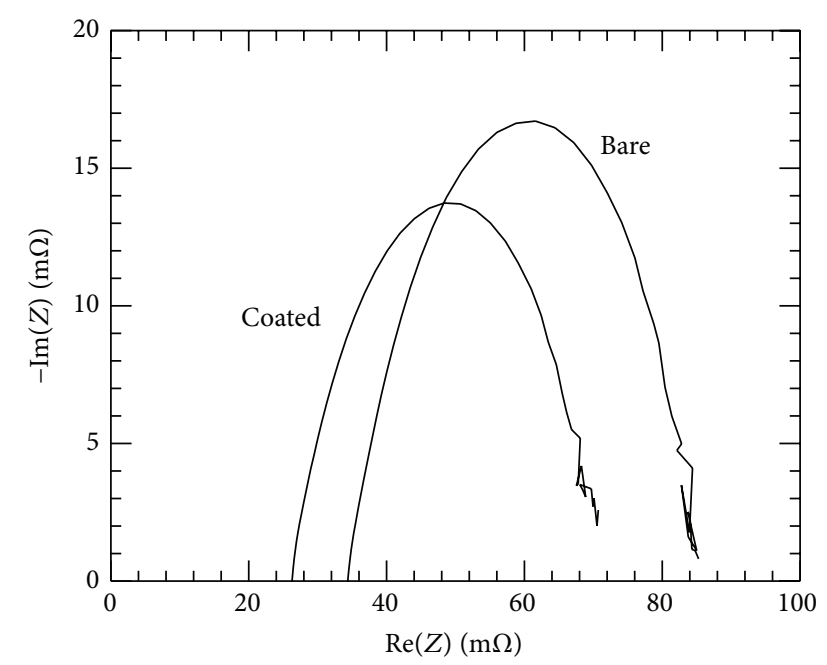

FIGURE 7: Cole-cole plots for the impedance measurement of the fuel cells assembled with the bare stainless steel bipolar plates or those coated with the CNT/PTFE composite film.

decreased with an increase in the current. The decrease of output voltage is originated from the IR drop, which occurred by the current flows in the inner resistance of the fuel cell.

Figure 6(b) shows the dependence of the current on the output power for the fuel cells. The fuel cell assembled with the bare SS bipolar plate showed the maximum output power of $140 \mathrm{~mW} / \mathrm{cm}^{2}$. The coating of the CNT/PTFE composite film increased the maximum output power to $180 \mathrm{~mW} / \mathrm{cm}^{2}$, which is 1.3 times higher than that of the bare SS bipolar plate.

Figure 7 shows the cole-cole plots for the impedance measurement of the fuel cells assembled with the bare SS bipolar plates or those coated with the CNT/PTFE composite film. The fuel cells showed a semicircular curve in the negative imaginary impedance $\left(-Z_{\mathrm{img}}\right)$ region. The line shapes for these fuel cells were almost the same. The semicircular curve was shifted to lower value on the real impedance $\left(Z_{\text {real }}\right)$ axis by the coating of CNT/PTFE composite film. The inner impedance of fuel cells is briefly assumed to consist of a capacitance $(C)$, a parallel resistance $\left(R_{p}\right)$ against the capacitance, and a series resistance $\left(R_{s}\right)$ against the parallel circuit of the capacitance, because the cole-cole plot for fuel cells shows the semicircular curve $[16,30]$. The shift of cole-cole plot indicates that the coating of the CNT/PTFE composite film on the bipolar plate decreases the series resistance from $340 \mathrm{~m} \Omega$ to $260 \mathrm{~m} \Omega$. The series resistance is originated from contact resistance between bipolar plate and MEA and proton conductivity in Nafion film and so forth [31]. Coating of the electrically conductive CNT/PTFE composite film decreases the contact resistance resulting in the series resistance. In the previous report $[16,30]$, the CNT dispersion was formed by using the ultrasonic homogenizer. The CNT/PTFE composite film, whose conductivity was $5 \mathrm{~S} / \mathrm{cm}$ at the CNT concentration of $25 \mathrm{wt} . \%$, was formed using the CNT dispersion and was applied to the bipolar plates of fuel cell. As a result, the coating of composite film increased the maximum power of fuel cell to 1.2 times. On the other hand, the CNT/PTFE composite film, which was prepared in this study, increases the maximum power to 1.3 times, which is higher than that of previous report, because the electrical conductivity of this film has higher value of $22 \mathrm{~S} / \mathrm{cm}$. The wet-jet milling method achieves increasing the output power of fuel cell by forming electrically conductive CNT/PTFE film and applying it to the bipolar plate.

\section{Summary}

The CNT dispersion was successfully formed by the wet-jet milling method. The dispersion had features such as time stability and low viscosity, although the CNT dispersion has high CNT concentration of $1 \mathrm{wt} . \%$. The CNT/PTFE composite film shows the high electrical conductivity of $22 \mathrm{~S} / \mathrm{cm}$, when the CNT dispersion, which is produced by the wetjet milling method, is used as a constituent of the composite film. These results are because the wet-jet milling process exfoliated individual CNTs from the CNT agglomerates and disperses them to the water uniformly.

The highly conductive CNT/PTFE composite film was applied to the bipolar plate of fuel cell. The coating of the composite film increased the output power of fuel cell to 1.3 times, because of a decrease in the contact resistance between bipolar plate and MEA. The improved output power results from forming good CNT dispersion as a constituent of the CNT/PTFE composite film by the wet-jet milling process.

\section{Conflict of Interests}

The authors declare that there is no conflict of interests regarding the publication of this paper.

\section{Acknowledgments}

This work was supported by JSPN KAKENHI Grant no. 26420683. The author would like to thank Mr. Y. Miyamoto of the Technical Service Coordination Office, Tokai University, for the SEM investigation and Mr. K. Sano of Jokoh Co., Ltd., for technical supports of wet-jet milling method.

\section{References}

[1] M. S. Dresselhaus, G. Dresselhaus, and P. Avouris, Carbon Nanotubes: Synthesis, Properties and Applications, Springer, Berlin, Germany, 2001.

[2] D. Tasis, N. Tagmatarchis, A. Bianco, and M. Prato, "Chemistry of carbon nanotubes," Chemical Reviews, vol. 106, no. 3, pp. 1105-1136, 2006.

[3] W. B. Choi, D. S. Chung, J. H. Kang et al., "Fully sealed, highbrightness carbon-nanotube field-emission display," Applied Physics Letters, vol. 75, no. 20, pp. 3129-3131, 1999.

[4] Q. H. Wang, M. Yan, and R. P. H. Chang, "Flat panel display prototype using gated carbon nanotube field emitters," Applied Physics Letters, vol. 78, no. 9, pp. 1294-1296, 2001.

[5] H. Yi, "Anodic stripping voltammetric determination of mercury using multi-walled carbon nanotubes film coated glassy carbon electrode," Analytical and Bioanalytical Chemistry, vol. 377, no. 4, pp. 770-774, 2003. 
[6] A. C. Dillon, K. M. Jones, T. A. Bekkedahl, C. H. Kiang, D. S. Bethune, and M. J. Heben, "Storage of hydrogen in single-walled carbon nanotubes," Nature, vol. 386, no. 6623, pp. 377-379, 1997.

[7] K. M. Liew, Z. X. Lei, and L. W. Zhang, "Mechanical analysis of functionally graded carbon nanotube reinforced composites: a review," Composite Structures, vol. 120, pp. 90-97, 2015.

[8] G. Mittal, V. Dhand, K. Y. Rhee, S.-J. Park, and W. R. Lee, "A review on carbon nanotubes and graphene as fillers in reinforced polymer nanocomposites," Journal of Industrial and Engineering Chemistry, vol. 21, pp. 11-25, 2015.

[9] R. Andrews, D. Jacques, M. Minot, and T. Rantell, "Fabrication of carbon multiwall nanotube/polymer composites by shear mixing," Macromolecular Materials and Engineering, vol. 287, no. 6, pp. 395-403, 2002.

[10] M. J. Biercuk, M. C. Llaguno, M. Radosavljevic, J. K. Hyun, A. T. Johnson, and J. E. Fischer, "Carbon nanotube composites for thermal management," Applied Physics Letters, vol. 80, no. 15, pp. 2767-2769, 2002.

[11] T. Fukushima, A. Kosaka, Y. Yamamoto et al., "Dramatic effect of dispersed carbon nanotubes on the mechanical and electroconductive properties of polymers derived from ionic liquids," Small, vol. 2, no. 4, pp. 554-560, 2006.

[12] M. Kim, Y.-B. Park, O. I. Okoli, and C. Zhang, "Processing, characterization, and modeling of carbon nanotube-reinforced multiscale composites," Composites Science and Technology, vol. 69, no. 3-4, pp. 335-342, 2009.

[13] Q. Zhao, Y. Shen, M. Ji, L. Zhang, T. Jiang, and C. Li, "Effect of carbon nanotube addition on friction coefficient of nanotubes/hydroxyapatite composites," Journal of Industrial and Engineering Chemistry, vol. 20, no. 2, pp. 544-548, 2014.

[14] F. Du, J. E. Fischer, and K. I. Winey, "Coagulation method for preparing single-walled carbon nanotube/poly(methyl methacrylate) composites and their modulus, electrical conductivity, and thermal stability," Journal of Polymer Science. Part B: Polymer Physics, vol. 41, no. 24, pp. 3333-3338, 2003.

[15] N. Rungraeng, Y.-C. Cho, S. H. Yoon, and S. Jun, "Carbon nanotube-polytetrafluoroethylene nanocomposite coating for milk fouling reduction in plate heat exchanger," Journal of Food Engineering, vol. 111, no. 2, pp. 218-224, 2012.

[16] Y. Show, T. Nakashima, and Y. Fukami, "Anticorrosion coating of carbon nanotube/polytetrafluoroethylene composite film on the stainless steel bipolar plate for proton exchange membrane fuel cells," Journal of Nanomaterials, vol. 2013, Article ID 378752, 7 pages, 2013.

[17] Y. Y. Huang and E. M. Terentjev, "Dispersion of carbon nanotubes: mixing, sonication, stabilization, and composite properties," Polymers, vol. 4, no. 1, pp. 275-295, 2012.

[18] R. Bandyopadhyaya, E. Nativ-Roth, O. Regev, and R. Yerushalmi-Rozen, "Stabilization of Individual Carbon Nanotubes in Aqueous Solutions," Nano Letters, vol. 2, no. 1, pp. 25-28, 2002.

[19] A. Aglan, A. Allie, A. Ludwick, and L. Koons, "Formulation and evaluation of nano-structured polymeric coatings for corrosion protection," Surface and Coatings Technology, vol. 202, no. 2, pp. 370-378, 2007.

[20] J. Sandler, M. S. P. Shaffer, T. Prasse, W. Bauhofer, K. Schulte, and A. H. Windle, "Development of a dispersion process for carbon nanotubes in an epoxy matrix and the resulting electrical properties," Polymer, vol. 40, no. 21, pp. 5967-5971, 1999.

[21] N. Pierard, A. Fonseca, J.-F. Colomer et al., "Ball milling effect on the structure of single-wall carbon nanotubes," Carbon, vol. 42, no. 8-9, pp. 1691-1697, 2004.
[22] T. Sekitani, H. Nakajima, H. Maeda et al., "Stretchable activematrix organic light-emitting diode display using printable elastic conductors," Nature Materials, vol. 8, no. 6, pp. 494-499, 2009.

[23] S. Ata, K. Kobashi, M. Yumura, and K. Hata, "Mechanically durable and highly conductive elastomeric composites from long single-walled carbon nanotubes mimicking the chain structure of polymers," Nano Letters, vol. 12, no. 6, pp. 27102716, 2012.

[24] H. Yoon, M. Yamashita, S. Ata, D. N. Futaba, T. Yamada, and K. Hata, "Controlling exfoliation in order to minimize damage during dispersion of long SWCNTs for advanced composites," Scientific Reports, vol. 4, article 3907, 2014.

[25] K. Kobashi, S. Ata, T. Yamada, D. N. Futaba, M. Yumura, and K. Hata, "A dispersion strategy: dendritic carbon nanotube network dispersion for advanced composites," Chemical Science, vol. 4, no. 2, pp. 727-733, 2013.

[26] Y. Imai, D. Shimamoto, and Y. Hotta, "Effect of wet jet milling of carbon nanotube on electrical properties of polymer nanocomposites," Materials Chemistry and Physics, vol. 148, no. 3, pp. 1178-1183, 2014.

[27] G. Matijašić and A. Glasnović, "Influence of dispersed phase characteristics on rheological behavior of suspensions," Chemical and Biochemical Engineering Quarterly, vol. 16, no. 4, pp. 165-172, 2002.

[28] S. Kirkpatrick, "Percolation and conduction," Reviews of Modern Physics, vol. 45, no. 4, pp. 574-588, 1973.

[29] H. Xia and M. Song, "Preparation and characterization of polyurethane-carbon nanotube composites," Soft Matter, vol. 1, no. 5, pp. 386-394, 2005.

[30] Y. Show and K. Takahashi, "Stainless steel bipolar plate coated with carbon nanotube (CNT)/polytetrafluoroethylene (PTFE) composite film for proton exchange membrane fuel cell (PEMFC)," Journal of Power Sources, vol. 190, no. 2, pp. 322-325, 2009.

[31] M. Ciureanu and R. Roberge, "Electrochemical impedance study of PEM fuel cells. Experimental diagnostics and modeling of air cathodes," Journal of Physical Chemistry B, vol. 105, no. 17, pp. 3531-3539, 2001. 

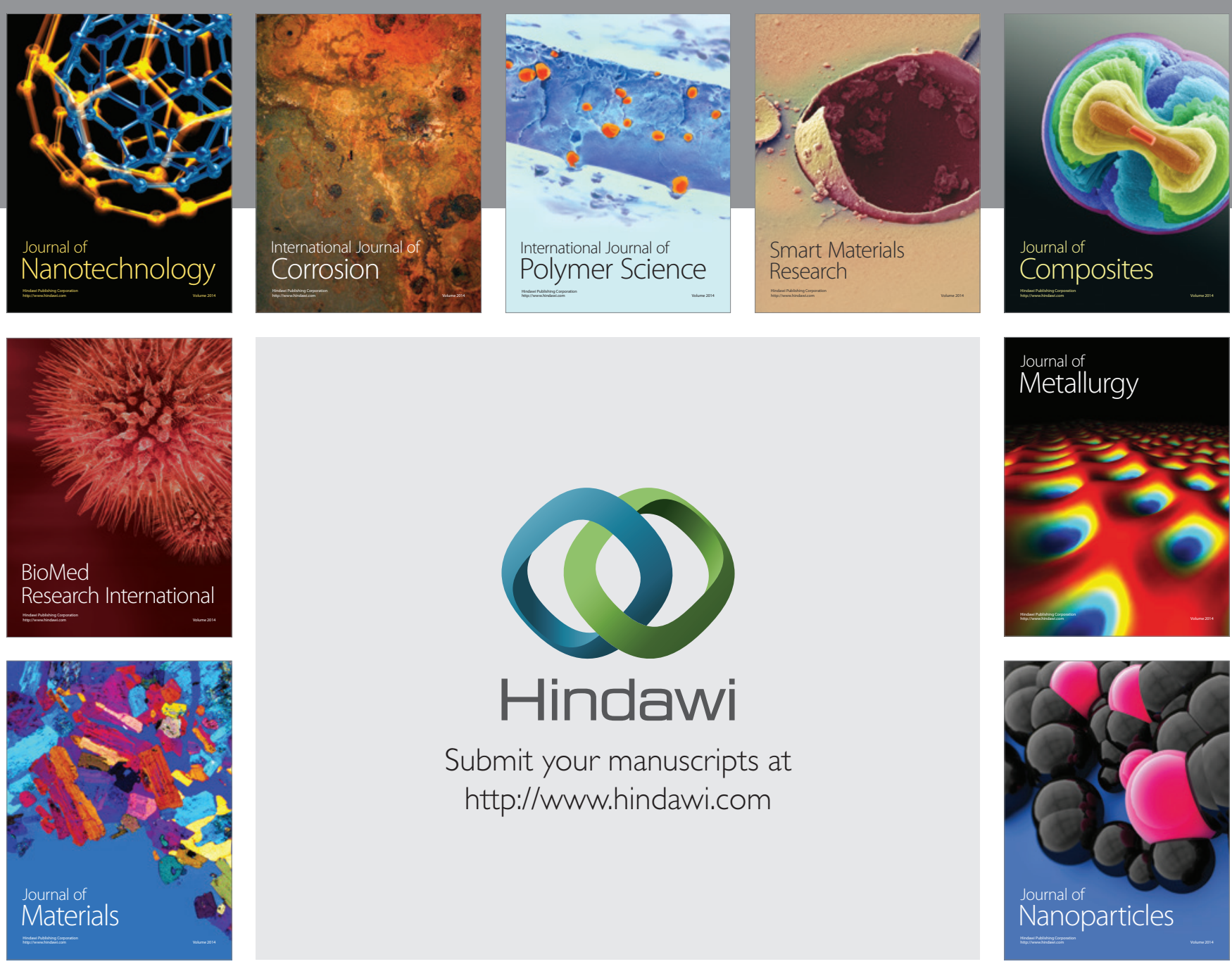

Submit your manuscripts at http://www.hindawi.com
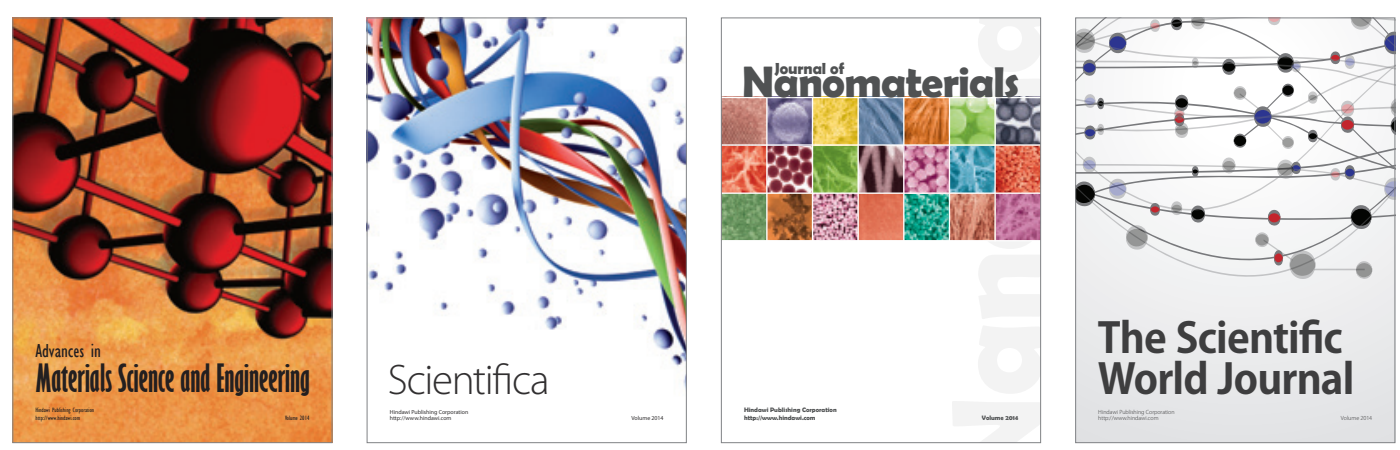

\section{The Scientific World Journal}
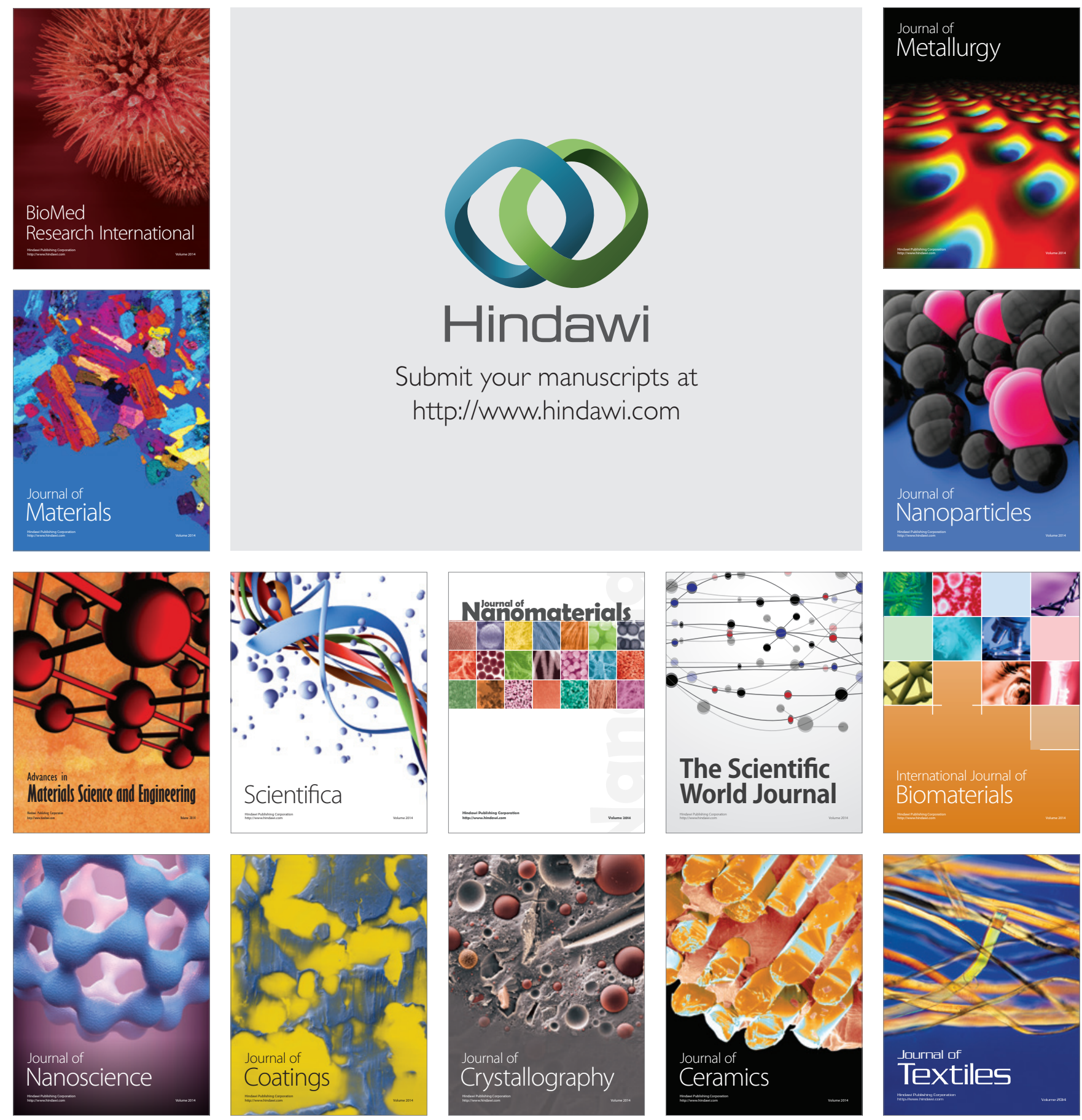